\section{$\underset{\substack{\text { hommes } \\ \text { \& migrations }}}{ }$}

\section{Hommes \& migrations}

Revue française de référence sur les dynamiques

migratoires

$1324 \mid 2019$

Religion et discrimination

\title{
Benoît Cohen, Mohammad, ma mère et moi
}

Paris, Flammarion, 2018, 288 p., $19 €$

\section{Catherine Guilyardi}

\section{(2) OpenEdition}

\section{Journals}

\section{Édition électronique}

URL : https://journals.openedition.org/hommesmigrations/8905

DOI : 10.4000/hommesmigrations.8905

ISSN : 2262-3353

\section{Éditeur}

Musée national de l'histoire de l'immigration

\section{Édition imprimée}

Date de publication : 1 janvier 2019

Pagination : 172-173

ISBN : 978-2-919040-44-5

ISSN : 1142-852X

\section{Référence électronique}

Catherine Guilyardi, «Benoît Cohen, Mohammad, ma mère et moi », Hommes \& migrations [En ligne], 1324 | 2019, mis en ligne le 01 janvier 2019, consulté le 08 janvier 2022. URL : http:// journals.openedition.org/hommesmigrations/8905; DOI : https://doi.org/10.4000/ hommesmigrations.8905 


\section{Benoît Cohen \\ Mohammad, ma mère et moi}

Paris, Flammarion, 2018, 288 pages, 19 euros.

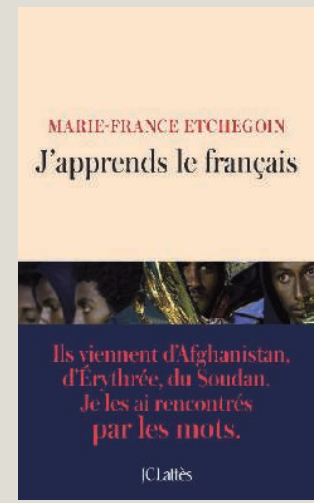

En cette fin d'année 2018, alors que la mort d'un traducteur afghan pour l'armée française - à qui Paris avait refusé un 
visa - défraie la chronique, le livre de Benoît Cohen sur l'accueil par sa mère d'un ancien traducteur afghan résonne aux oreilles du lecteur. Ce livre est le témoignage d'un homme, mi-sceptique, mi-admiratif, qui observe sa mère âgée ouvrir les portes de son bel hôtel particulier parisien à un jeune homme cabossé par la guerre et l'exil.

Le réalisateur de Tu seras un homme et de Nos enfants chéris vient de quitter la France pour les États-Unis lorsqu'il apprend la décision de sa mère, Marie-France. Arrivé à New York en pleine élection de Trump, il observe, sidéré, ses amis américains privilégiés et éduqués s'étonner de l'arrivée du populisme dans leur pays. Ils n'avaient pas vu venir - ou voulu voir venir - le retour de la peur. Quand, à Paris, sa mère - comme d'autres habitants - décide de faire œuvre d'hospitalité, Benoît Cohen considère comme une urgence le fait de raconter l'histoire de Mohammad, ce jeune homme de 23 ans qui vient de s'installer dans la chambre de bonne de la grande maison vide de sa mère, veuve, dans le $7^{\mathrm{e}}$ arrondissement.

Benoît Cohen observe la relation complexe et forte qui se tisse entre Marie-France et ce jeune homme étranger qui réapprend doucement à faire confiance. La vie n'a pas fait de cadeaux à Mohammad, mais il sait qu'il a eu de la chance par rapport à d'autres. Embauché comme interprète de terrain par une armée européenne à Kaboul, il gagne bien sa vie quand les Occidentaux décident de se retirer. Comme tous ceux qui ont collaboré avec les armées étrangères qui se battent contre les Talibans, il se retrouve en tête de la liste des hommes à abattre. Mohammad ne reçoit aucun soutien de ceux qui l'ont embauché. Il décide de fuir par ses propres moyens vers le Sri Lanka pour obtenir une aide de l'ONU. En vain. Après deux ans de galère sur l'île, il obtient finalement l'aide d'un fonctionnaire du consulat français et se retrouve à Paris.

Sans papiers, il devient victime de tous ceux qui abusent de sa fragilité, mais la détermination de ce jeune homme est sans limite. Il décide de s'inscrire dans une association d'aide et croise la route de Marie-France. On ne s'habitue pas si vite au confort et encore moins à la gentillesse quand on a été rejeté depuis si longtemps. Son attitude désarçonne la vieille dame qui veut lui donner autant que ce qu'elle a donné à ses fils. Un ami psychiatre de la famille aide le jeune homme à reprendre pied et Benoît Cohen multiplie les allersretours avec New York pour écrire un livre - ce livre - dont Mohammad accepte le principe assez vite.

L'histoire de Mohammad finit bien ou plutôt commence enfin, grâce aux gens extraordinaires qu'il croise sur sa route et à son incroyable détermination. Car il souhaite une chose plus que tout: entrer à Sciences Po. Benoît Cohen nous offre, ici, le récit d'une rencontre riche et belle, illustration - encore - de l'hospitalité de plus en plus fréquente de la société civile française depuis 2015, alors que les politiques migratoires sont de plus en plus restrictives.

Catherine Guilyardi 